\title{
Differential Expression of c-fos mRNA Within Neurocircuits of Male Hamsters Exposed to Acute or Chronic Defeat
}

\author{
S. Kollack-Walker, ${ }^{1}$ C. Don, ${ }^{1}$ S. J. Watson and H. Akil \\ Mental Health Research Institute, University of Michigan, Ann Arbor, MI, USA.
}

Key words: social stress, defeat, c-fos, aggression, chronic

\begin{abstract}
Chronic exposure to stress has been implicated in physical and mental illness, and such experiences can produce alterations in the connectivity and number of neurones within the brain to variations in the expression of specific genes. The purpose of this study was to determine how repeated exposure to social defeat affects neuronal activation patterns within the male Syrian hamster brain. Toward this end, the levels c-fos mRNA were compared among three groups: (1) handled controls (HC); (2) acutely defeated males (AD); and (3) chronically defeated males (15 min aggression daily, 7 days) exposed to an acute challenge (CD). Plasma glucocorticoids were also measured and compared among groups as an index of neuroendocrine activity. The results show a selective pattern of habituation of immediate early gene expression within the brains of chronically defeated males. In particular, c-fos mRNA levels were significantly decreased within the paraventricular nucleus of the hypothalamus (PVN), supraoptic nucleus of the hypothalamus, septohypothalamic nucleus, intermediate subdivision of the lateral septum, central amygdaloid nucleus, and the amygdalohippocampal area in the CD group exposed to an acute challenge when compared to males defeated only once. In contrast, c-fos expression within the anterior and ventromedial nuclei of the hypothalamus, dorsal periaqueductal grey, dorsal raphe, cuneiform nucleus, and locus coeruleus did not differ between AD and CD groups. Similarly, plasma levels of cortisol and corticosterone in CD group were equivalent to those observed after a single defeat experience. We discuss the possibility that decreased expression of c-fos mRNA within the PVN and other brain regions of defeated animals-in the presence of elevated adrenal steroids-may reflect a state of molecular plasticity that could alter neurotransmission within the limbic-hypothalamopituitary-adrenocortical axis. In contrast, brain areas that maintain relatively high levels of c-fos mRNA following repeated defeat may reflect processes less likely to adapt such as defensive behaviour.
\end{abstract}

Situations initially perceived as stressful often take on a different meaning with repetition. In many instances, individuals learn to cope with the event and find repeated exposures less stressful. This phenomenon has been termed habituation, and is clearly adaptive in that animals learn to limit their stress response only to situations that are lifethreatening, requiring 'fight or flight' responses. In contrast, in other situations, individuals may not learn an effective strategy for coping with stress, either resulting from an individual's genetic makeup or prior experiences, or from repeated exposure to stressful events that are intense, unpre- dictable and uncontrollable. As a consequence, such individuals continue to find repetitive exposure to the stressor just as stressful, if not more, than the initial experience. An inability to adapt to stress (i.e. chronic stress) has been implicated in the aetiology of physical disease (1) and mental illness (e.g. depression (2)).

Social defeat provides a naturalistic model of stress characterized by aggressive interactions that are intense, unpredictable, and with no real opportunity for the defeated animal to control the outcome of the situation. Chronic exposure to aggressive, dominant males in mixed-sex rat colonies results

Correspondence to: Dr Sara Kollack-Walker, Mental Health Research Institute, University of Michigan, 205 Zina Pitcher Place, Ann Arbor, MI 48109-0720, USA (e-mail: skwalker@umich.edu).

${ }^{1}$ Primary co-authors.

(C) 1999 Blackwell Science Ltd 
in numerous behavioural and physiological changes in the subordinate animals including weight loss, decreases in eating and social behaviour (aggression, mating), increases in defensiveness and alcohol consumption, reduced longevity, alterations in sleep, and changes in the hypothalamic-pituitaryadrenocortical (HPA) and gonadal (HPG) axes indicative of chronic stress (visible burrow system, reviewed in (3)). Similar consequences have also been reported in subordinate animals following only brief, intermittent periods of aggressive interactions (4-11). Of interest, many of the changes observed in animals repeatedly or chronically exposed to social defeat resemble the symptoms of depression in humans (reviewed in $(12,13))$. Moreover, social stress has been implicated in the aetiology of mental illness (14). Understanding how the brain responds to repeated social defeat in animals may prove very useful in understanding the effects of social stress in humans.

Recently, we described the activation of distinct neurocircuits within the brains of male hamsters defeated only once by an aggressive, dominant male (15). Would exposure to multiple defeat experiences alter this pattern of neuronal activation? To our knowledge, only two studies have addressed this issue. Matsuda and colleagues (16) reported persistent expression of Fos protein, a marker of neuronal activation, throughout the brains of male mice $24 \mathrm{~h}$ after the fifth, but not the first, daily defeat experience. Stimulus-induced expression of c-fos mRNA and Fos protein, products of the c-fos protooncogene, is typically brief, with levels rising and disappearing within 2-4 h (17). Persistent levels of Fos protein within the brains of these males $24 \mathrm{~h}$ after the last defeat experience would suggest continual stimulation of those neurones and possibly enhanced activation of neural circuits mediating the behavioural and physiological changes associated with chronic social stress.

In contrast, Martinez and colleagues (18) reported that repeated exposure to social defeat in male rats resulted in a significant decline in Fos immunostaining in some brain regions following an acute challenge to values not different from control, while other brain areas continued to express significant levels of Fos protein above control. These authors discuss the possibility that significant decreases in Fos immunostaining upon repeated defeat reflect the adaptation of some physiological processes, while continued expression of Fos protein reflects processes less likely to habituate such as olfaction. In this regard, they cite previous work showing that repeated exposure to restraint also results in a selective reduction of Fos immunostaining within some brain regions of the male rat, and that this adaptation in c-fos expression was correlated with decreases in heart rate and corticosterone levels upon repeated exposure. However, similar measurements of cardiovascular and neuroendocrine regulation were not taken in animals repeatedly stressed by defeat. Therefore, it is not known if decreases in immediate early gene expression actually reflect adaptation in the physiological response of these animals.

At present, it is unclear if there are species-specific patterns of neuronal activation associated with chronic social stress, or if the differences noted above reflect differences in experimental design. Furthermore, the functional significance of patterns of c-fos expression that persist, or habituate, within the brain following repeated exposure to social defeat is unknown. The purpose of the present study was to determine how exposure to multiple defeat experiences alters c-fos expression within specific brain regions of the male Syrian hamster in response to an acute defeat challenge, and the relationship of those changes to defeat-induced secretion of cortisol and corticosterone.

\section{Materials and methods}

\section{Behavioural testing}

Twenty-eight male hamsters were singly housed for one week with food and water available ad libitum. During this period of isolation, 19 males were handled daily by placing each animal into the vacated home cage of another male for $15 \mathrm{~min}$, while nine males were defeated daily by placing each animal into the home cage of an aggressive, dominant animal for $15 \mathrm{~min}$. In this study (and different from our previous work (15)) each male, handled or defeated, was exposed to the home cage environment, empty or occupied, of a series of different males over the course of the experiment. Although some of the pairings were repeated throughout the week of pretests, on the last day all pairings were novel. Thus, handled control males $(\mathrm{HC}, \mathrm{n}=10)$ were exposed to empty home cages of males not used for handling pretests, acutely defeated males ( $A D, n=9)$ were exposed for the first time to aggressive, dominant males, and chronically defeated males $(C D, n=9)$ were placed into the home cage of aggressive, dominant animals not used previously in aggression pretests. The goal of this design was to ensure that any resultant changes in c-fos expression in the brains of chronically defeated males would be associated with repeated exposure to defeat and not simply repeated exposure to another male (i.e. reduced arousal, aggression, or novelty).

All behavioural tests were conducted within the first $4 \mathrm{~h}$ of the animals' dark period under dim illumination (lights off at \pm 12.30 p.m.). Immediately following testing on the last day, each animal was rapidly transported to another room, and decapitated. Trunk blood was collected in heparinized plastic vials on ice and stored at $-20{ }^{\circ} \mathrm{C}$ until samples could be assayed for plasma levels of cortisol and corticosterone. Brains were removed, frozen in isopentane $\left(-30\right.$ to $\left.-50{ }^{\circ} \mathrm{C}\right)$, and then stored in $-80^{\circ} \mathrm{C}$ until the tissue was processed for c-fos mRNA in-situ hybridization histochemistry.

\section{Radioimmunoassays}

Cortisol was assayed using the Coat-A-Count Cortisol kit obtained from Diagnostic Products Corp. (Los Angeles, CA, USA). Intra-assay variability was $<10 \%$.

Corticosterone was assayed using a highly specific antibody developed in our laboratory and characterized by Dr D. L. Helmreich (Mental Health Research Institute, University of Michigan, MI, USA). Specific details of this radioimmunoassay have been published previously (19). Intra-assay variability was $<10 \%$

\section{In-situ hybridization histochemistry}

A series of $10-\mu \mathrm{m}$ sections were collected from each brain and mounted on poly L-lysine coated slides. The sections were taken at $200 \mu \mathrm{m}$ intervals (or greater) except at the level of the PVN in which sections were collected at $100 \mu \mathrm{m}$ intervals. Slides were fixed in $4 \%$ paraformaldehyde and then processed for c-fos in-situ hybridization histochemistry using ${ }^{35} \mathrm{~S}$-labelled, 680 -nucleotide cRNA probe as previously described (15). The only change made to the published protocol was that sections were not deproteinated with proteinase $\mathrm{K}$ as we find that this step is unnecessary. All slides were exposed to Kodax BioMax MR X-ray film (Rochester, NY, USA) for 1 week. The slides were subsequently dipped in Kodak NTB2 emulsion and stored in light-tight boxes for 12 weeks at $4{ }^{\circ} \mathrm{C}$. The emulsion-dipped slides were then developed in Kodax D-19 developer, counterstained with cresyl violet, dehydrated in a graded series of alcohols, cleared in xylene, and coverslipped with Permount.

\section{Analysis of behaviour}

To determine if the intensity of fighting was similar between the two defeated groups, we devised the following 'intensity scale' based on the amount of offense or interest shown by the DOM toward the SUB male during the 30 min agonistic encounter: LOW-little to no offence or interest shown by the DOM male at any time during testing (1 point); LOWMODERATE-some offense shown by DOM male during testing, although it is often mild not resulting in biting attacks nor elicitation of the full submissive posture from the SUB male (1.5 points); MODERATE-reasonably 
strong levels of offense are shown by DOM male early in the behavioural test involving active chasing and biting attacks, and often eliciting the full submissive posture from the SUB male; in general, the DOM male shows decreasing interest in offensive responding later in the test (2 points); MODERATE-HIGH-strong levels of offense are shown by DOM male throughout the test, with intermittent periods of time devoted toward investigating the cage or grooming allowing the SUB male to rest (2.5 points); HIGH-strong levels of offense are shown throughout the behavioural test with active chasing and biting attacks; in general, there are very few periods in which the DOM male is not directing his attention toward the SUB animal (3 points).

This study was completed using three cohorts of animals that were run at different times during the year; each cohort contained one or more animals in each of the three groups. For the first cohort of animals, all defeat pretests as well as the behavioural tests on the last day were videotaped. However, for the second and third cohorts, only notes were taken for the pretests and behavioural tests on the last day. As a consequence, ratings of the intensity of offense shown by the DOM male were based on notes recorded on the last day for all animals, and when possible, videotapes were reviewed before assigning a value. The ratings for all defeated males in each group were averaged, and then compared statistically between $\mathrm{AD}$ and $\mathrm{CD}$ groups using a Student's $t$-test $(\mathrm{P}<0.05)$.

\section{Analysis of c-fos $m R N A$ expression}

The levels of c-fos mRNA per brain region per group were quantified from X-ray film (NIH Image software) using previously designed templates (15). The only exception involved the bed nucleus of the stria terminalis (BNST) in which we measured c-fos expression within the anterolateral subdivision (BNSTal) instead of the anterior BNST (which previously included both the anteromedial and anterolateral subdivisions). The location of each template is illustrated in Fig. 1; the sections used in this illustration have been modified from the rat brain atlas (20). In general, two optical density measurements were taken per brain region per animal. The optical density values were corrected for background (i.e. subtraction of optical density obtained from a region of white matter-corpus callosum), multiplied by the area sampled to produce an integrated optical density measurement, and then averaged to produce one data point for each brain region in each animal. These data points were then averaged per group and compared statistically. Specific location of signal was confirmed from emulsion-dipped slides.

To determine if the intensity of fighting was comparable between acutely defeated and chronically defeated animals, the mean rating of offense by DOM males was compared between $\mathrm{AD}$ and $\mathrm{CD}$ groups using a Student's $t$ test $(\mathrm{P}<0.05)$. A one-factor ANOVA was used to determine the effects of chronic defeat on glucocorticoid secretion and c-fos expression within specific brain regions, with post-hoc comparisons made between groups using the Tukey-Kramer Multiple Comparisons Test $(\mathrm{P}<0.05)$. The data were logtransformed as necessary. All statistical comparisons were made using Instat 2.01 software.

\section{Results}

\section{Behavioural observations}

In the majority of DOM-SUB encounters (16/18 or $88 \%)$, the intruder male behaved submissively in response to offensive aggression shown by the dominant resident animal. There were two exceptions. First, one male in the AD group actually became dominant to the resident male previously used in aggression pretests. Second, one male in the CD group was mistakenly exposed to a different stress paradigm on the last day instead of defeat. Data for these two 'non-defeated' animals were not included in the analysis of behaviour, glucocorticoid secretion, or c-fos expression within select brain regions. The results presented are based on a revised number of animals per group: $\mathrm{HC}(n=10), \mathrm{AD}(n=8), \mathrm{CD}$ $(n=8)$.

Ratings of offense were made for the last aggression test according to the following scale (described in detail under Materials and Methods): LOW (1 point), LOWMODERATE (1.5 points), MODERATE (2 points), MODERATE-HIGH (2.5 points), HIGH (3 points). These ratings were based on the DOM male's behaviour toward the intruder (SUB) during the entire 30-min test. However, there were three behavioural tests that were modified because the SUB male was injured (two tests for the AD group and one for the CD group). As a result of injury, the DOM-SUB males in each pair were separated by placing the wire mesh cover between the two animals for the remainder of the test. We have elected to give a rating of HIGH ( 3 points) to these tests because the intensity of fighting was strong enough to produce injury. Although separation might lessen glucocorticoid secretion and possibly activate other brain circuits associated with recuperative processes, the pattern of c-fos expression at the 30 min time-point should still reflect physiological and behavioural processes associated with an intense aggressive encounter.

Figure 2 illustrates the average level of aggression received by SUB males in the AD and CD groups. Although there was a slight tendency for lower levels of offense to be experienced by the chronically defeated males as compared to those defeated only once $(\mathrm{CD} / \mathrm{AD}=0.81)$, this trend for reduced levels of offence was not statistically significant.

\section{Glucocorticoid secretion}

Cortisol and corticosterone were significantly elevated in the AD group relative to $\mathrm{HC}$ males (Fig. 3). Although there was also a tendency for lower levels of total glucocorticoids to be present in the $\mathrm{CD}$ group relative to the $\mathrm{AD}$ group $(\mathrm{CD} / \mathrm{AD}=$ 0.78 ), this difference was not statistically significant (Fig. 3 ).

\section{c-fos $m R N A$ expression}

Figure 4 illustrates the distribution of c-fos mRNA within select brain regions of $\mathrm{HC}, \mathrm{AD}$ and $\mathrm{CD}$ males. The sections illustrated for the $\mathrm{AD}$ and $\mathrm{CD}$ groups were taken from animals that had experienced MED-HIGH levels of offensive aggression (as defined in this study). The integrated optical density measurements for each brain area in $\mathrm{HC}, \mathrm{AD}$ and CD groups are provided in Table 1 . In addition, Table 1 lists the $\mathrm{CD} / \mathrm{AD}$ ratio for each brain region providing an index of the degree of change observed in the $\mathrm{CD}$ group compared to the AD group.

In all brain areas analysed, c-fos mRNA levels were significantly elevated in the AD group compared to handled controls. Based on statistical comparisons among HC, AD and $\mathrm{CD}$ groups, three distinct patterns of change were observed in c-fos expression in the brains of chronically defeated males: (1) habituation, (2) partial habituation, and (3) no habituation (Fig. 5). In the anterior subdivision of the paraventricular nucleus of the hypothalamus (PVNant), c-fos mRNA levels decreased significantly in the CD group relative to acutely defeated males, with no difference observed relative to control (habituation, $\mathrm{CD} / \mathrm{AD}$ ratio $=0.40$; Figs $5 \mathrm{~A}, 6 \mathrm{~B})$. This pattern was observed in three additional brain areas including amygdalohippocampal area (AHi), central nucleus of the amygdala (CeA) and the intermediate subdivision of the lateral septum ( $\mathrm{LSi}$ ) (Figs 5D, 6A). In the 
550 c-fos mRNA following acute or chronic defeat

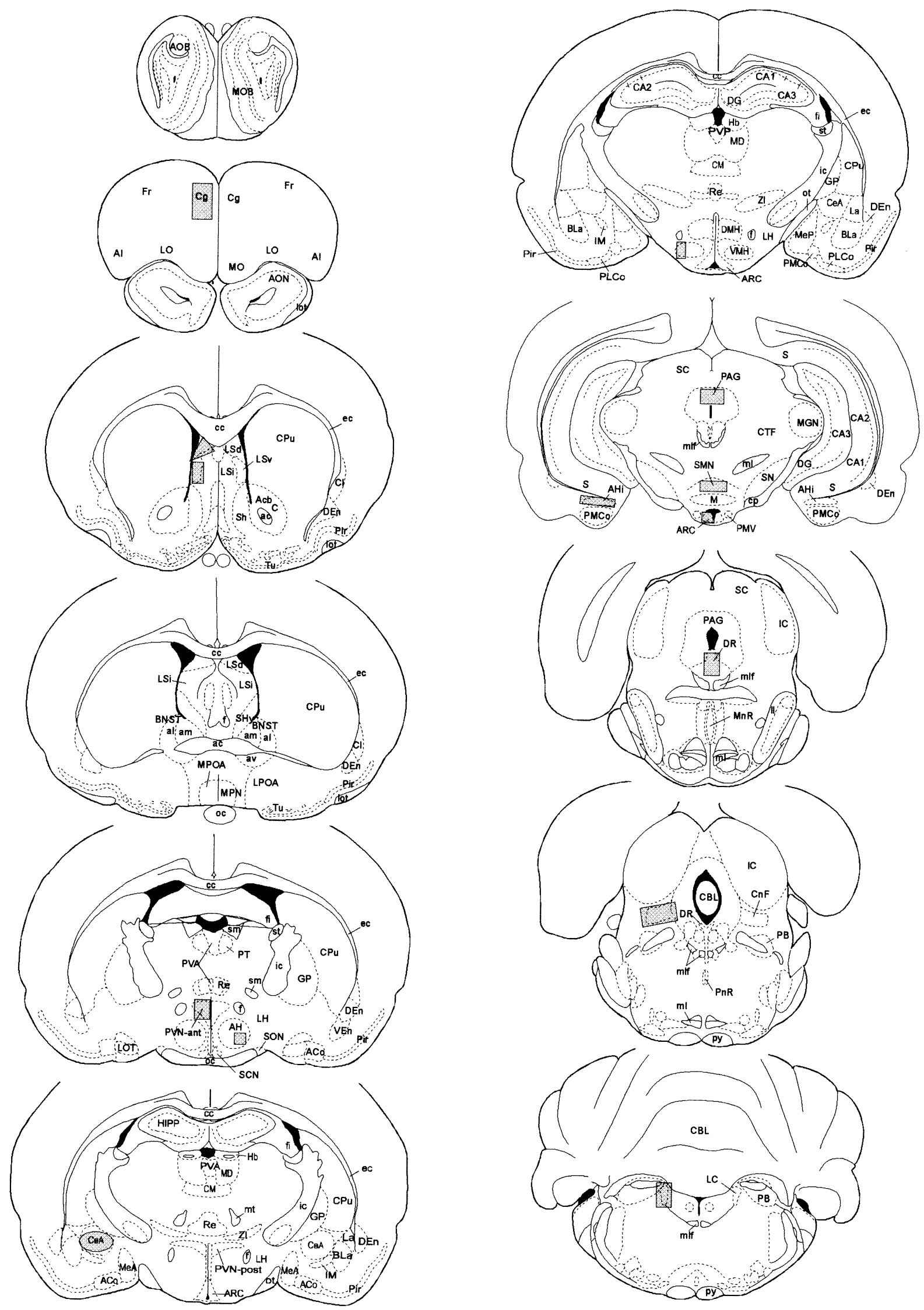

FIG. 1. The location of templates used to sample optical density measurements within specific brain regions in each animal. 


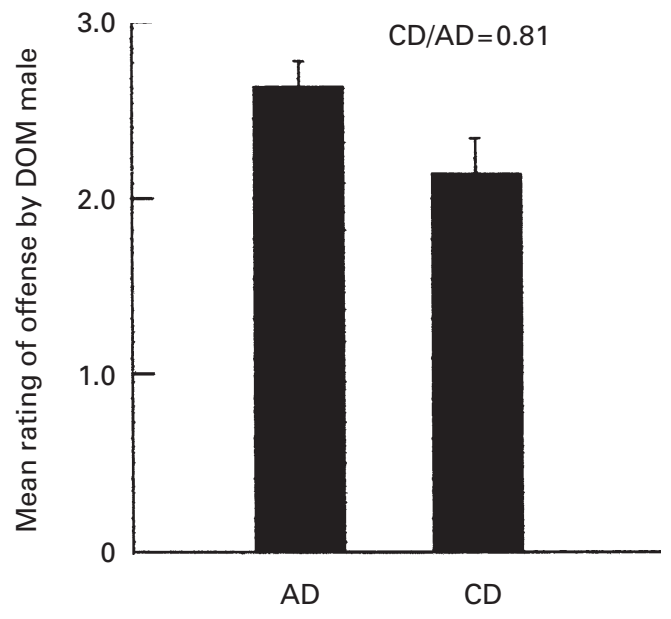

FIG. 2. The mean ratings of offense by the DOM male $( \pm$ SEM $)$ shown toward animals in the $\mathrm{AD}$ and $\mathrm{CD}$ groups.

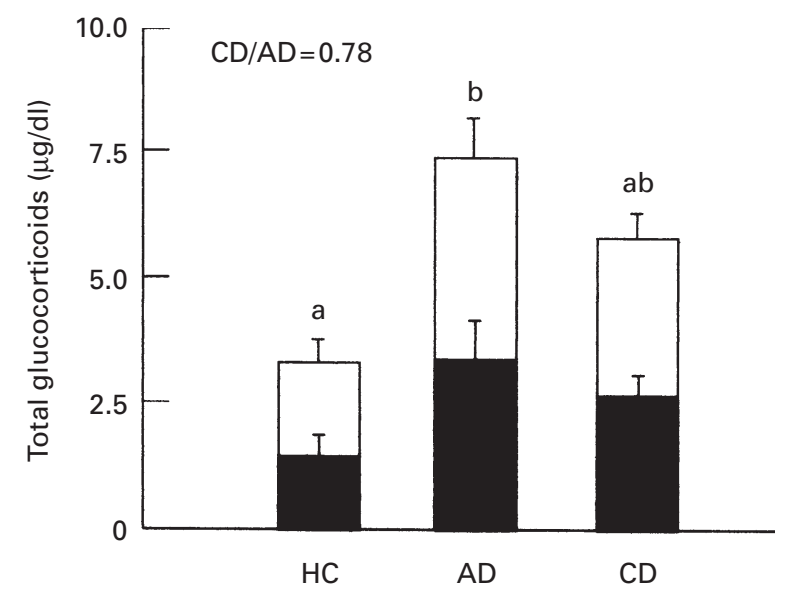

FIG. 3. Level of total glucocorticoids within $\mathrm{HC}$, AD and CD groups. For each group, the cortisol data is presented as a black bar (mean \pm SEM), and the corticosterone data is presented as an open bar (mean \pm SEM).

septohypothalamic nucleus (SHy), c-fos mRNA levels were also decreased significantly in the $\mathrm{CD}$ group relative to $\mathrm{AD}$ group, with levels also differing from $\mathrm{HC}$ suggestive of a partial change ( partial habituation, $\mathrm{CD} / \mathrm{AD}$ ratio $=0.60$; Figs $5 \mathrm{~B}, 6 \mathrm{C})$. In the anterior hypothalamic nucleus $(\mathrm{AH})$, no difference was observed between $\mathrm{CD}$ and $\mathrm{AD}$ groups, with both groups possessing elevated levels of c-fos expression above control (no habituation, $\mathrm{CD} / \mathrm{AD}$ ratio $=0.84$; Figs $5 \mathrm{C}$, 6в). A similar pattern of change was observed within the cuneiform nucleus $(\mathrm{CnF})$, the dorsal raphe (DR), the locus coeruleus (LC), the dorsal subdivision of the periaqueductal grey (PAGd) and the lateral subdivision of the ventromedial nucleus of the hypothalamus (VMH-1) (Figs 5D, 6D).

The analysis of c-fos expression within several additional brain regions in $\mathrm{CD}$ males was inconclusive, with values in the $\mathrm{CD}$ group being not different from either the $\mathrm{HC}$ or $\mathrm{AD}$ groups; brain regions in this category included the arcuate nucleus of the hypothalamus (ARC), the anterolateral subdivision of the bed nucleus of the stria terminalis (BNSTal), the cingulate cortex $(\mathrm{Cg})$, dorsal $(\mathrm{LSd})$ and ventral $(\mathrm{LSv})$ subdivisions of the lateral septum, the supramammillary nucleus (SMN) and the medial preoptic area (MPOA) (Fig. 5D). The $\mathrm{CD} / \mathrm{AD}$ ratio for the majority of these brain regions ranged from 0.61 to 0.82 , suggestive of either partial habituation or no change in c-fos mRNA levels. In contrast, the $\mathrm{CD} / \mathrm{AD}$ ratio for the BNSTal was much less $(0.44)$, lying within the range of other brain areas, like the PVNant, that showed a more striking degree of habituation.

At the request of one of our reviewers, we extended our analysis of c-fos expression within the $\mathrm{HC}, \mathrm{AD}$ and $\mathrm{CD}$ groups to the supraoptic (SON) and suprachiasmatic (SCN) nuclei of the hypothalamus. In the $\mathrm{SCN}$, we found no evidence of selective activation of this nucleus following defeat, nor any changes occurring in response to repeated defeat (Table 1). In the SON, we did find selective activation following acute defeat with habituation of c-fos expression seen after repeated defeat $(\mathrm{AD}>\mathrm{CD}>\mathrm{HC}$; see Table 1 and Figs $5 \mathrm{D}, 6 \mathrm{~B})$. The $\mathrm{CD} / \mathrm{AD}$ ratio for $\mathrm{SON}$ was 0.29 , in the range of changes occurring within $\mathrm{CeA}$ and PVNant.

\section{Discussion}

In this study, we report selectivity in habituation of c-fos expression within distinct brain regions following repeated exposure to defeat. Although a broad range of responses was observed, comparison of c-fos mRNA levels between CD and $\mathrm{AD}$ groups revealed two main patterns of expression: habituation (complete and partial) or no change. In brief, the levels of c-fos mRNA were significantly reduced within the AHi, CeA, LSi, PVNant, SON and SHy of chronically defeated male hamsters exposed to an acute challenge in comparison to males defeated only once. It seems likely that a similar process is occurring within BNSTal(low $\mathrm{CD} / \mathrm{AD}$ ratio), although this change did not achieve statistical significance. In contrast, a number of brain regions showed levels of c-fos expression in chronically defeated males that were comparable to those observed in AD group: $\mathrm{AH}, \mathrm{CnF}, \mathrm{DR}, \mathrm{LC}, \mathrm{PAGd}$ and VMH-1. Analysis of c-fos expression in other brains areas was less clear as the CD group did not differ from either the $\mathrm{HC}$ or $\mathrm{AD}$ groups. However, comparing $\mathrm{CD} / \mathrm{AD}$ ratios within these brain regions to that observed for $\mathrm{SHy}(0.60)$ and $\mathrm{AH}(0.84)$ may be suggestive of changes occurring in some of these areas which did not reach statistical significance in the present study.

In general, our results are analogous to the findings of Martinez et al. (18) in which repeated exposure of male rats to defeat resulted in a selective pattern of adaptation of Fosimmunostaining within the brain. Following an acute defeat exposure, male rats show an increase in the number of Fospositive neurones within several brain regions including the lateral septum, dorsolateral BNST, PVN (dorsal, lateral and medial subdivisions), CeA, central grey, DR and LC. After the tenth daily defeat the lateral septum, CeA, medial subdivision of the PVN, and LC showed no increases in Fos immunostaining relative to control, while the dorsolateral BNST, PVN (dorsal and lateral subdivisions), central grey and DR continued to express increased levels of Fos protein above control. Similar to their observations, we report reduced c-fos mRNA levels within CeA and PVNant after repeated defeat experiences in the male hamster, while the 
552 c-fos mRNA following acute or chronic defeat
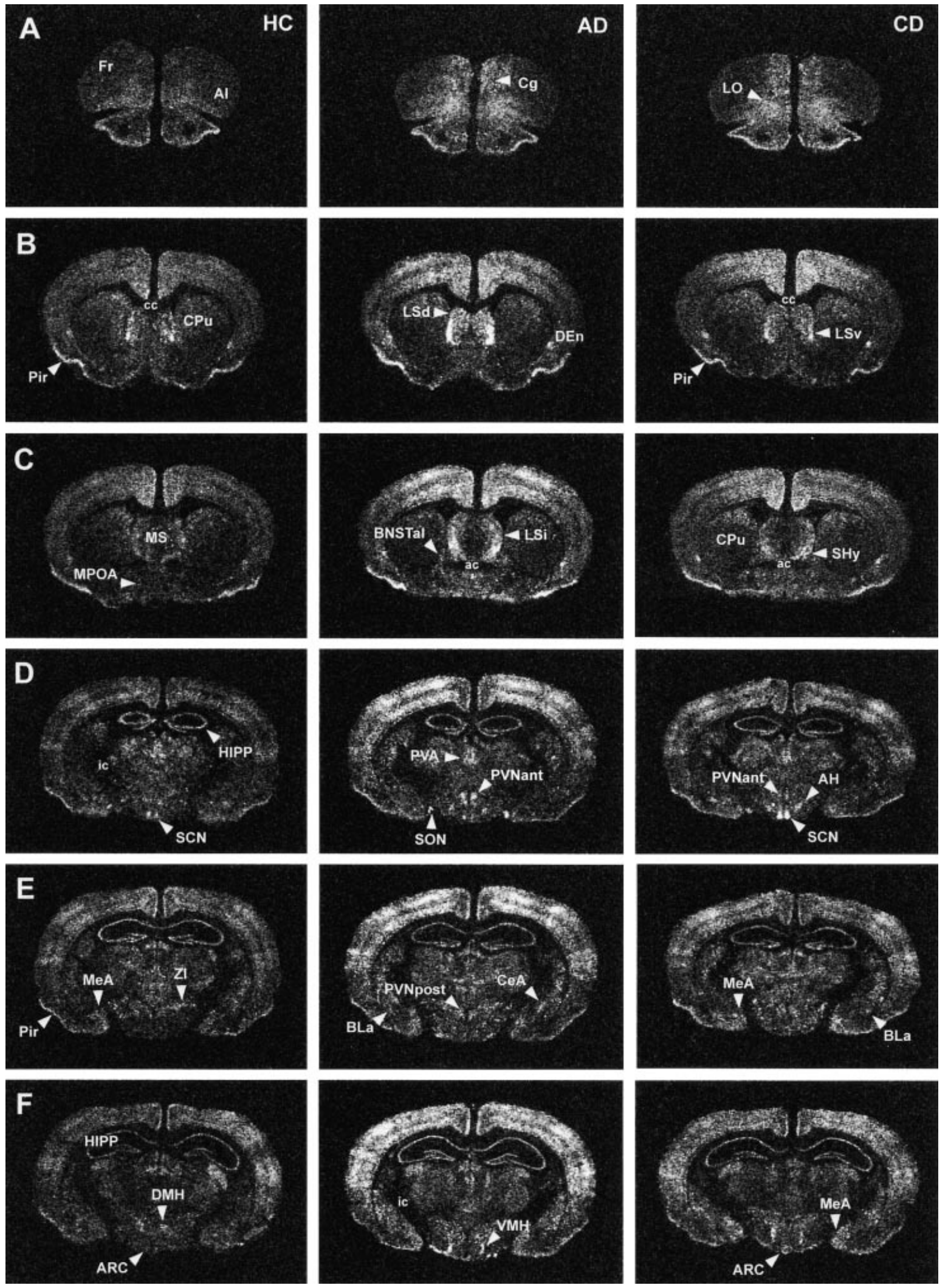

(C) 1999 Blackwell Science Ltd, Journal of Neuroendocrinology, 11, 547-559 

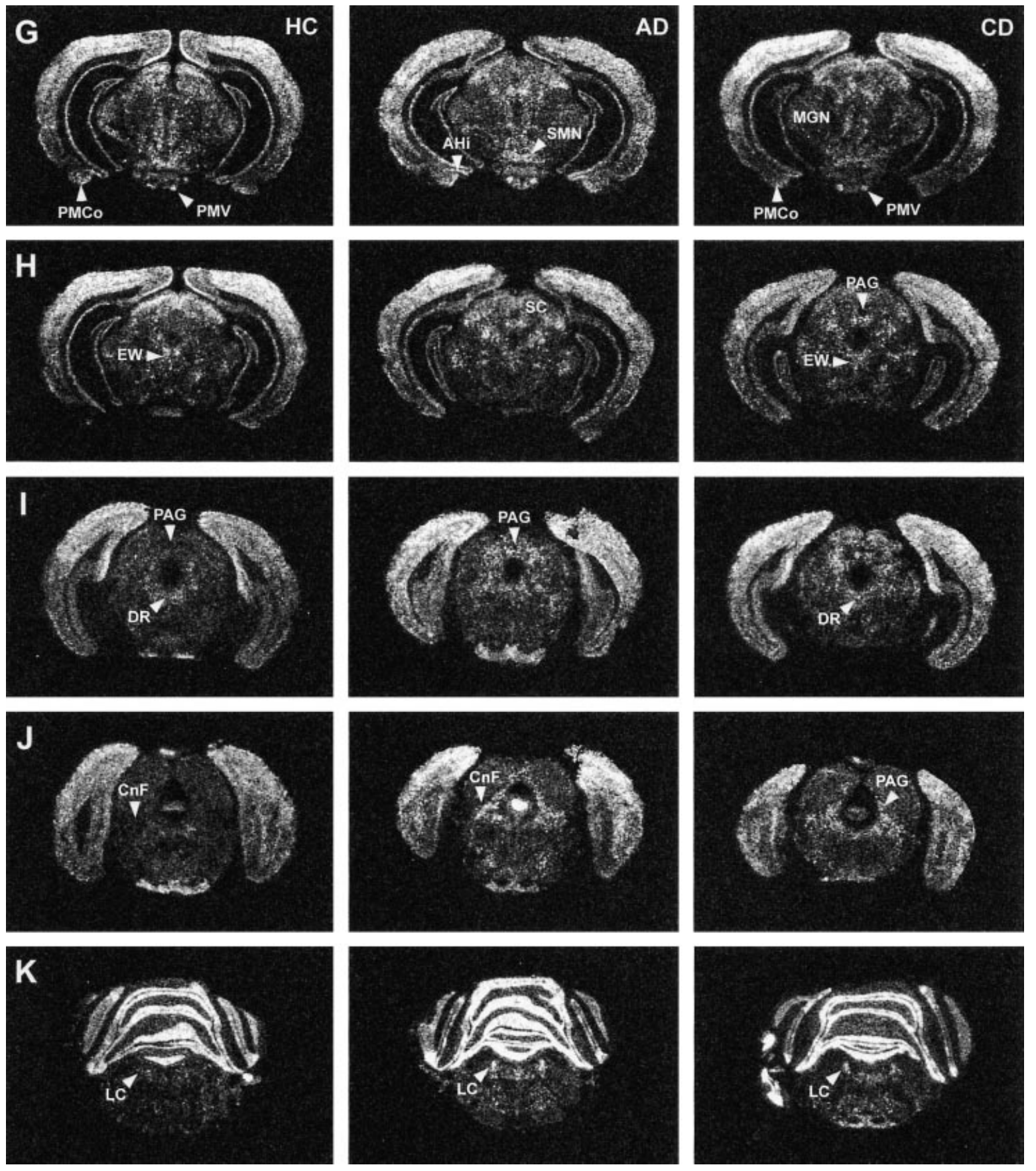

FIG. 4. A series of photomicrographs illustrating the overall distribution of c-fos mRNA throughout successively rostrocaudal levels of the brain from animals in the $\mathrm{HC}, \mathrm{AD}$ and $\mathrm{CD}$ groups.

PAG (central grey) and DR continued to show a c-fos response equivalent to that observed acutely. However, in our study, the LC did not show decreased levels of c-fos mRNA, while the anterolateral BNST showed a strong tendency for less c-fos mRNA following repeated exposure to defeat. Also, while most brain areas seemed to show less Fos-immunostaining after multiple defeat experiences in the male rat when compared to animals defeated only once (18), our data suggest a greater distinction with some brain areas clearly showing evidence of habituation of c-fos expression while other brain areas did not. The reason for these differences is presently unknown, although it is possible that a longer exposure to defeat in the male rat (i.e. 10 days $v s$ 7 days) may have led to a greater degree of habituation in cfos expression observed throughout the brain.

In contrast to our findings, Matsuda et al. (16) reported that exposure of repeatedly defeated male mice to an acute challenge increased the number of Fos positive neurones throughout the brain that was equivalent if not slightly higher than that observed in acutely defeated males. Furthermore, 
TABle 1. Mean Integrated Optical Density Measurements ( \pm SEM) Per Brain Area in HC, AD and CD Groups. CD/AD Ratios Are Calculated To Illustrate the Degree of Change Between AD and CD Groups.

\begin{tabular}{|c|c|c|c|c|}
\hline Nucleus & $\mathrm{HC}$ & $\mathrm{AD}$ & $\mathrm{CD}$ & $\mathrm{CD} / \mathrm{AD}$ ratio \\
\hline \multicolumn{5}{|l|}{ Forebrain } \\
\hline BNSTal & $198 \pm 46^{\mathrm{a}}$ & $812 \pm 196^{\mathrm{b}}$ & $358 \pm 125^{\mathrm{a}, \mathrm{b}}$ & 0.44 \\
\hline Cg Cortex & $7250 \pm 1602^{\mathrm{a}}$ & $16,689 \pm 2483^{b}$ & $12,059 \pm 1616^{\mathrm{a}, \mathrm{b}}$ & 0.72 \\
\hline MPOA & $942 \pm 178^{\mathrm{a}}$ & $2215 \pm 410^{\mathrm{b}}$ & $1824 \pm 355^{\mathrm{a}, \mathrm{b}}$ & 0.82 \\
\hline \multicolumn{5}{|l|}{ Amygdala } \\
\hline $\mathrm{AHi}$ & $2623+608^{a}$ & $7833+949^{b}$ & $4995+397^{a}$ & 0.64 \\
\hline $\mathrm{CeA}$ & $270 \pm 109^{\mathrm{a}}$ & $1769 \pm 419^{\mathrm{b}}$ & $466 \pm 232^{\mathrm{a}}$ & 0.26 \\
\hline \multicolumn{5}{|l|}{ Septum } \\
\hline LSd & $3446+520^{\mathrm{a}}$ & $10,498+1867^{\mathrm{b}}$ & $6448+1688^{a, b}$ & 0.61 \\
\hline $\mathrm{LSi}$ & $3541 \pm 706^{\mathrm{a}}$ & $11,176 \pm 1600^{\mathrm{b}}$ & $5408+1158^{\mathrm{a}}$ & 0.48 \\
\hline LSv & $5687 \pm 1176^{\mathrm{a}}$ & $13,075 \pm 1491^{\mathrm{b}}$ & $8868 \pm 1593^{\mathrm{a}, \mathrm{b}}$ & 0.68 \\
\hline SHy & $2597 \pm 472^{\mathrm{a}}$ & $12,091 \pm 1053^{\mathrm{b}}$ & $7272 \pm 1183^{\mathrm{c}}$ & 0.60 \\
\hline \multicolumn{5}{|l|}{ Hypothalamus } \\
\hline AH & $1006+415^{\mathrm{a}}$ & $5578+856^{\mathrm{b}}$ & $4687+887^{\mathrm{b}}$ & 0.84 \\
\hline ARC & $944 \pm 213^{\mathrm{a}}$ & $2625 \pm 436^{\mathrm{b}}$ & $2092 \pm 397^{\mathrm{a}, \mathrm{b}}$ & 0.80 \\
\hline PVN-anterior & $1591+286^{\mathrm{a}}$ & $6685+1091^{\mathrm{b}}$ & $2693+392^{\mathrm{a}}$ & 0.40 \\
\hline $\mathrm{SCN}$ & $4571 \pm 555$ & $5940 \pm 1132$ & $6896 \pm 984$ & - \\
\hline SMN & $6374 \pm 1188^{\mathrm{a}}$ & $12,838 \pm 1307^{\mathrm{b}}$ & $9904 \pm 1460^{\mathrm{a}, \mathrm{b}}$ & 0.77 \\
\hline SON & $644 \pm 280^{\mathrm{a}}$ & $6388 \pm 1347^{\mathrm{b}}$ & $1883 \pm 472^{\mathrm{c}}$ & 0.29 \\
\hline VMH-lateral & $831+118^{a}$ & $7542+897^{\mathrm{b}}$ & $5175+976^{\mathrm{b}}$ & 0.69 \\
\hline \multicolumn{5}{|l|}{ Midbrain } \\
\hline DR & $941 \pm 143^{a}$ & $2484 \pm 244^{\mathrm{b}}$ & $1904 \pm 357^{b}$ & 0.77 \\
\hline $\mathrm{CnF}$ & $818+186^{a}$ & $8483+740^{\mathrm{b}}$ & $7565+1049^{b}$ & 0.89 \\
\hline PAG-dorsal & $1765 \pm 191^{\mathrm{a}}$ & $12,143 \pm 1694^{b}$ & $11,557 \pm 1987^{b}$ & 0.95 \\
\hline \multicolumn{5}{|l|}{ Hindbrain } \\
\hline LC & $1091 \pm 236^{\mathrm{a}}$ & $5539 \pm 967^{b}$ & $4750 \pm 628^{b}$ & 0.86 \\
\hline
\end{tabular}

The statistical relationship among HC-AD-CD groups is shown in columns $2-4$. In brain regions showing an overall group effect, the ${ }^{\mathrm{a}},{ }^{\mathrm{b}}$ and ${ }^{\mathrm{c}}$ indicate the result of pairwise comparisons among HC, AD and CD groups; a significant difference in integrated optical density measurements between any two groups is indicated by different symbols.

such an exposure resulted in significant elevations in Fos protein that could be detected up to $24 \mathrm{~h}$ after the last (fifth) defeat experience. We did not find evidence for enhanced levels of c-fos mRNA within the brains of chronically defeated male hamsters when compared to males defeated only once. Furthermore, the adaptation observed in select brain regions following multiple defeat experiences in the hamster (and rat) would not explicitly support the concept of persistent expression of Fos protein(see below). The reason for differences in c-fos expression within the brains of male hamsters, rats and mice following repeated defeat is not known. However, the subordinate mice were housed in groups when they were not exposed to an aggressive, dominant conspecific. Therefore, it is possible that chronic exposure to social stress may have altered the behaviour of these animals in their home cage which contributed to enhanced activation observed 1-2 h after the defeat challenge, and to the 'persistent' levels of Fos protein reported $24 \mathrm{~h}$ after the final defeat experience.

Although repeated exposure of subordinate male hamsters to defeat did reduce c-fos mRNA levels in select brain regions following an acute challenge, this stress paradigm did not lead to a decline in the level of plasma glucocorticoids. Total glucocorticoids in the CD group were not statistically different from the levels found in the AD group, although the levels of cortisol and corticosterone in the CD group were also not different from control. Even more compelling, though, the $\mathrm{CD} / \mathrm{AD}$ ratio for total glucocorticoids $(0.78)$ was similar to the ratio observed for the intensity of fighting $(0.81)$ in which $\mathrm{AD}$ and $\mathrm{CD}$ groups did not differ from each other, and to the ratios for c-fos expression within the majority of brain regions that also showed no difference between $\mathrm{AD}$ and $\mathrm{CD}$ groups (range: 0.69-0.95). Furthermore, in a subsequent study with similar groups, we obtained the same finding that chronically defeated males exposed to an acute challenge possess an equivalent level of glucocorticoids to that of acutely defeated males, with both groups being significantly elevated above control (unpublished observations). In this latter study, basal levels of glucocorticoids in chronically defeated males were not different from the levels observed in handled controls (unpublished observations). Thus, it appears that male hamsters defeated daily for 1 week and then exposed to an acute challenge can secrete an equivalent level of glucocorticoids to that observed in males defeated only once, even though c-fos expression within the PVN of chronically defeated males is attenuated. Additional studies will be necessary to determine if this stress paradigm is associated with adaptive changes occurring at the level of the pituitary or adrenal gland, or in the rate of termination of the HPA axis response.

\section{Habituation of c-fos expression following repeated defeat: regulation of neuroendocrine neurocircuits?}

The PVN plays a critical role in the excitatory regulation of the pituitary-adrenal axis (reviewed in (21)). In the present study, expression of c-fos mRNA was significantly reduced in the PVN of male hamsters defeated multiple times when compared to animals defeated only once. This finding is in 

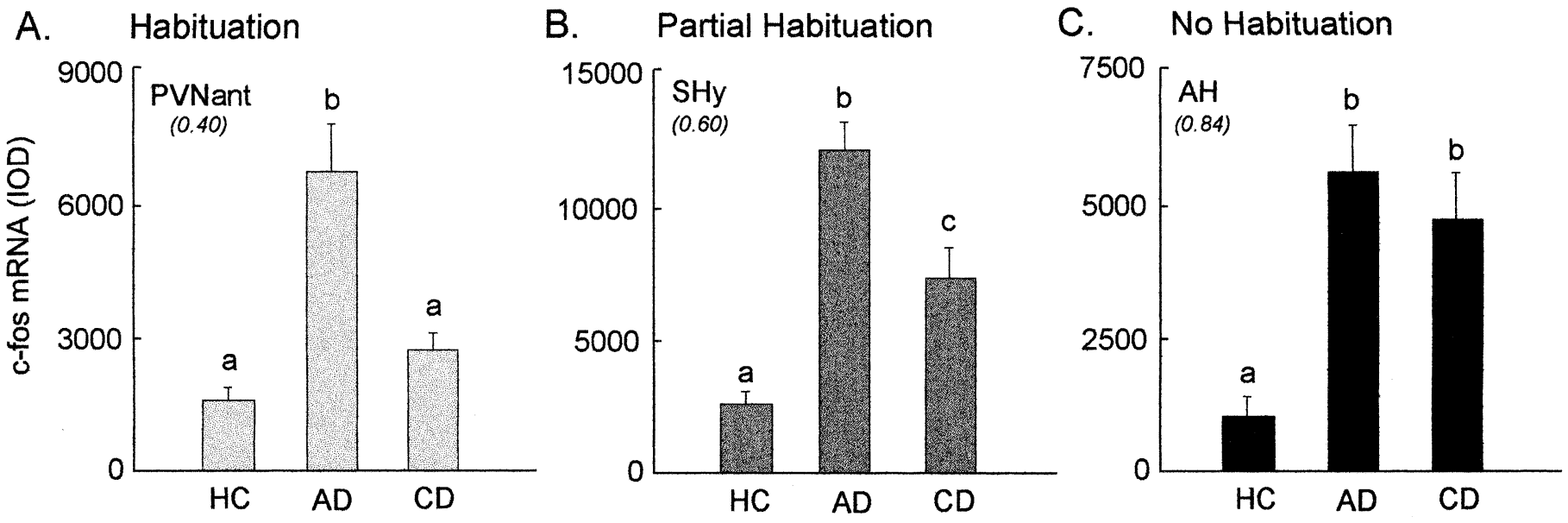

D.

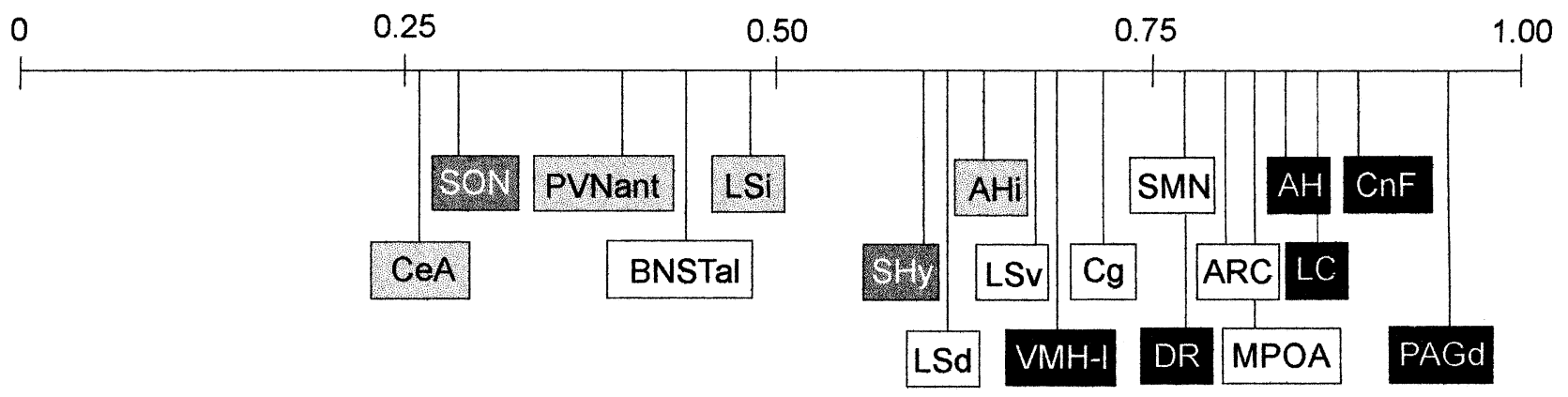

FIG. 5. Three distinct patterns of change were observed in c-fos expression in chronically defeated males relative to HC and AD groups. The data presented in the three graphs $(\mathrm{A}-\mathrm{C})$ represent the mean integrated optical density measurements $( \pm \mathrm{SEM})$ per brain area per group. 'Habituation' means that c-fos expression within a given brain region decreased in $\mathrm{CD}$ group relative to $\mathrm{AD}$ group, with levels not differing from control $(\mathrm{AD}>\mathrm{HC}=\mathrm{CD})$; this pattern was observed within PVNant (A), and within other brain areas (D, boxes with similar light grey shading). 'Partial habituation' indicates that c-fos expression within a given brain region decreased within $\mathrm{CD}$ group relative to $\mathrm{AD}$ group, but the level remain significantly elevated above control $(\mathrm{AD}>\mathrm{CD}>\mathrm{HC})$; this pattern was observed only within SHy (B,D, box with dark grey shading). 'No habituation' indicates that c-fos expression within a given brain region in CD group was not significantly different from the levels observed within the AD group, but both groups were significantly elevated above control $(\mathrm{AD}=\mathrm{CD}>\mathrm{HC})$; this pattern was observed within $\mathrm{AH}(\mathrm{C})$, and within other brain areas (D, black boxes). All of the brain areas analysed in this study are plotted in (D) according the $\mathrm{CD} / \mathrm{AD}$ ratios; areas with a low $\mathrm{CD} / \mathrm{AD}$ ratio are shown to the left, and those with higher ratios to the right. Brains areas surrounded by shading or black match the patterns illustrated in (A-C). Brain areas with no shading represent areas in the which the current statistical analysis was inconclusive, with levels of c-fos mRNA in CD group being not different from $\mathrm{HC}$ group or the AD group.

agreement with a number of studies reporting decreased expression of c-fos mRNA or Fos protein within the PVN following repeated exposure to social defeat (rat (18)), restraint $(22,23)$, immobilization $(24,25)$, or footshock (26).

Does habituation of c-fos expression mean less activation? The answer to this question may depend upon the type of stressor used. Melia et al. (27) reported a significant decrease in c-fos mRNA levels within the cortex, hippocampus, hypothalamus, septum and brainstem following repeated exposure to restraint stress. This decrease in immediate early gene expression was paralleled by a decline in plasma levels of glucocorticoids, and it was postulated that habituation of both responses was the result of decreased perception of restraint as being stressful. This finding was confirmed by Watanabe et al. (22) who also showed that repeated exposure to restraint stress decreased the levels of c-fos mRNA within the LC, raphe, central grey and PVN compared to acutely stressed group. Chen and Herbert (23) extended these findings by analysing additional brain areas and stress parameters (cardiovascular regulation and core body temperature). However, their basic conclusion was the same with respect to c-fos expression in the PVN: repeated exposure to restraint followed by an acute challenge decreases the level of Fos protein within the PVN, and these changes are accompanied by significant decreases in corticosterone and stress-induced tachycardia.

Umemoto et al. $(24,25)$ also demonstrated a reduction in Fos immunostaining and c-fos mRNA within the PVN of male rats repeated stressed by immobilization and then exposed to an acute immobilization challenge. However, they suggested that this decrease does not reflect habituation in stress responsiveness. They based this conclusion, in part, on data in their laboratory showing that CRH mRNA levels in the PVN of animals subjected to repeated immobilization stress followed by an acute challenge were higher than that of animals stressed acutely by immobilization (not published, 

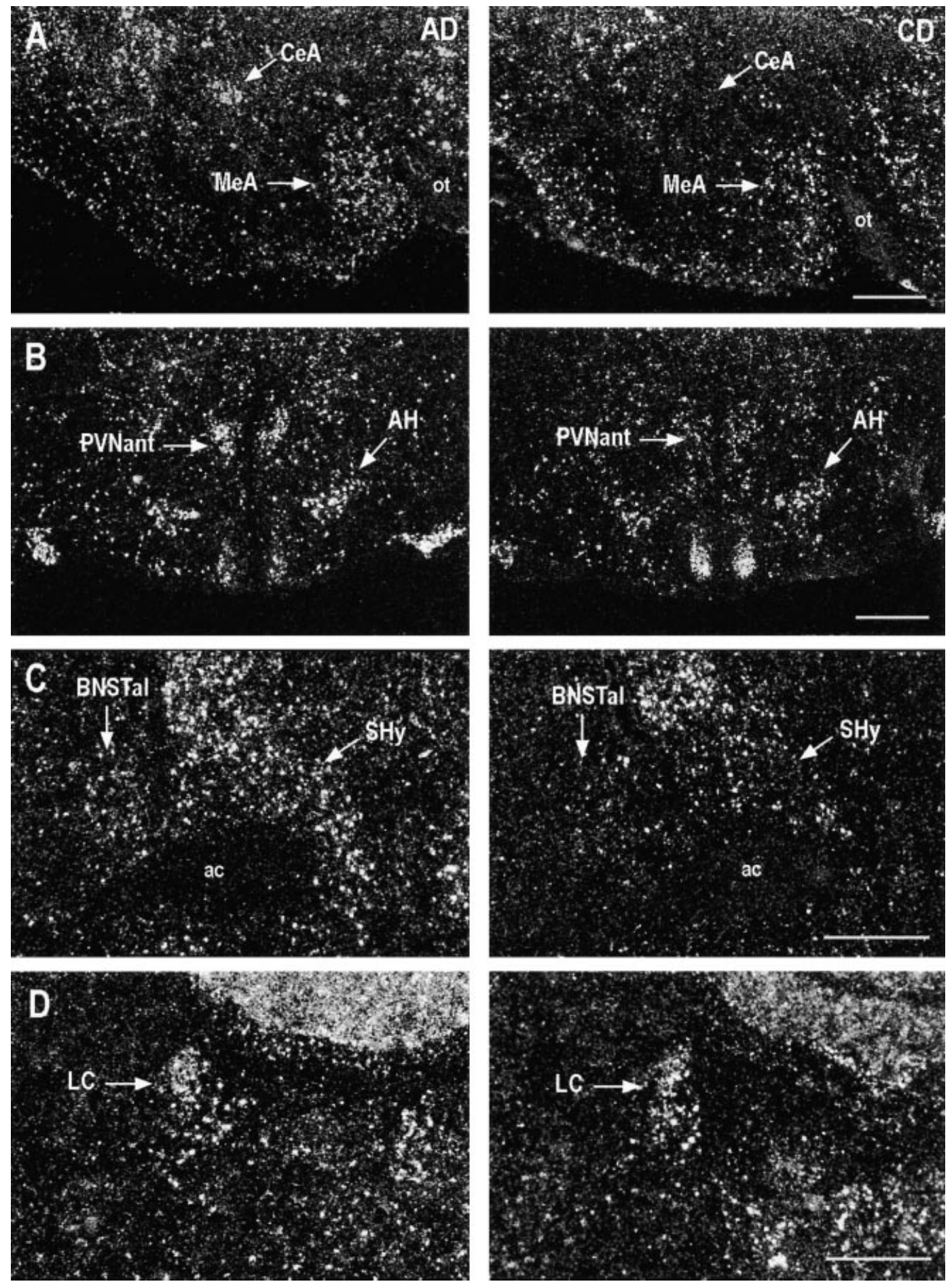

FIG. 6. A series of photomicrographs through the amygdala (A), hypothalamus (B), septum and BNST (C) and brainstem (D) illustrating differences in c-fos mRNA expression between AD group (left column) and CD group (right column). Scale bar $=300 \mu \mathrm{m}$.

but mentioned in (24)). In support of this thesis, Mamalaki et al. (28) demonstrated an up-regulation of CRH mRNA levels in the PVN of male rats repeatedly stressed by immobilization and then exposed to an acute challenge when compared to animals immobilized only once. Furthermore, the level of plasma corticosterone was elevated above control in all animals stressed on the last day by immobilization regardless of prior exposure to that stressor (28). Thus, while c-fos expression decreased within the PVN of animals repeatedly stressed by restraint or immobilization, the significance of that decrease to HPA axis function varied based on the stressor employed. 
In the present study, c-fos mRNA levels in PVNant were significantly lower in the CD group as compared to the AD group following a $30 \mathrm{~min}$ aggressive test, although the level of total glucocorticoids was similar between these two groups. This dissociation indicates that decreased expression of the immediate early gene, c-fos, within the PVN following repeated defeat is not associated with a reduction in stress responsiveness. In fact, the similarity of changes observed in this study to that reported following repeated exposure to immobilization stress suggests the possibility that $\mathrm{CRH}$ mRNA levels may be up-regulated in neurones of the PVN of chronically defeated male hamsters, a hypothesis we are currently testing.

Although the functional significance of a reduction in cfos mRNA levels within the PVN of CD males is presently unknown, such decreases may reflect a state of 'molecular plasticity' at the level of the neurone. Following an acute seizure, elevations in Fos protein have been implicated in short-term inhibition of c-fos mRNA levels (29). However, long-term inhibition of c-fos expression does not appear to be associated with increases in Fos (30). These latter authors discuss several mechanisms that may explain chronic adaptation: (1) elevations in Fos-related antigens (FRAs) (31), (2) inhibition of c-fos gene transcription by gene products regulated by Fos, and (3) alterations in the functional state of receptor-coupled second messenger systems and/or ion channels that may regulate expression of this immediate early gene. More recently, repeated exposure to a given stimulus has been shown to increase levels of chronic FRAs (32), which appear to be stable delta-Fos B proteins with half-lives on the order of days (33). Chronic FRAs result in persistent elevations in AP-1 binding $(32,33)$, which could provide a means for long-term inhibition of c-fos gene transcription (via interactions with an AP-1 site located in the promotor region of the c-fos gene) (29), as well as modulation of genes involved in neuroplasticity (34).

Are similar changes occurring in other brain regions that may modulate the activity of neurones within the PVN? In the present study, decreased levels of c-fos mRNA were also observed within AHi, CeA, LSi, SHy and SON (and possibly BNSTal) of chronically defeated males exposed to an acute defeat challenge when compared to males defeated only once. The similarity in habituation of c-fos expression observed within these brain regions and the PVN suggest the possibility that neuronal activity within these brain areas may be functionally linked. In support of this thesis, the CeA, lateral septum (and BNST) have all been implicated in regulation of the HPA axis (for review see (35)), although it has been suggested that this control is mediated via a multisynaptic pathway involving the MPOA (36). We did not find evidence for habituation of c-fos expression within the MPOA of chronically defeated males; however, it is possible that we may have missed such changes as a result of our sampling procedure (e.g. size and/or location of template used). Additional studies will be necessary to determine if the reduction of c-fos mRNA within these brain regions reflects processes leading to the adaptation observed within the PVN.

It is important to bear in mind, though, that changes can occur in parallel and not be causally related. For example, while the $\mathrm{CeA}$, lateral septum ( $\mathrm{SHy}$ ) and BNST have been shown to play a role in HPA axis regulation, these areas have also been implicated in autonomic responses (CeA (37-39)); $L S(40) ; B N S T(41,42))$ as well as anxiety or stress-related behaviours (CeA $(39,43,44)$; $L S(45,46)$; BNST $(41,47))$. Habituation of c-fos expression in these brain regions following repeated defeat could reflect alterations in any of these processes.

The AHi receives substantial input from several amygdaloid nuclei as well as from the ventral subiculum and adjacent parts of the hippocampal field $\mathrm{CA}_{1}$, and sends efferent projections to the SHy (referred to as LSv (48)) and to distinct subdivisions of the MPOA (anteroventral periventricular nucleus and medial part of the medial preoptic nucleus)(48). It is presently unknown as to what role the AHi area might play in regulation of the HPA axis, although activation of AHi has been reported following other stressors (e.g. electroconvulsive shock (49)).

The activation observed within the SON of AD males may reflect regulation of cardiovascular and body fluid homeostasis. During a stressful encounter, blood pressure and volume increases, and blood flow is redirected from the viscera and skin to organs critical for survival such as the brain and heart (reviewed in (50)). These changes are mediated, in part, by activation of the renin-angiotensin system which plays an important role in vasoconstriction, as well as stimulation of the release of vasopressin from magnocellular neurones within the PVN and SON via distinct neural pathways (reviewed in $(50,51))$. It is possible that expression of c-fos mRNA within the SON reflects the activation of vasopressinergic neurones involved in regulating blood volume, a hypothesis that will require further study.

\section{Non-habituation of c-fos expression following repeated defeat: regulation of behavioural neurocircuits?}

Equivalent levels of c-fos expression were observed within numerous brain regions following an aggressive encounter in both the acutely defeated and chronically defeated groups; these brain regions included: ventrolateral $\mathrm{AH}$, lateral $\mathrm{VMH}$, SMN, ARC, dorsal PAG, CnF, DR, LC. The slight trend for lower c-fos mRNA levels to be present in the chronic defeat group relative to acutely defeated males most likely reflects a tendency for lower levels of aggression to be displayed by dominant males on the last day of testing (note similarity in $\mathrm{CD}$ : AD ratios between c-fos expression within these brain areas and the level of aggression experienced). We believe that this decreasing trend is simply the result of using a subset of DOM males for the CD group that differed, in part, from the group used for the AD group. The selection of a DOM male to be used for behavioural testing on the last day was random, based solely on which DOM animals had not been used previously for aggression pretests with a given subordinate male. However, we cannot exclude the possibility that repeated exposure to defeat altered the behaviour of the subordinate animal in some way (e.g. increased willingness to submit), that subsequently reduced the amount of aggression displayed by the DOM male.

The reason that some brain regions show relatively high levels of c-fos mRNA following repeated exposure to social defeat, while others do not, is presently unknown. However, 
two possible explanations can be proposed. First, if a decrease in c-fos mRNA expression observed in some brain regions (e.g. PVN) following repeated defeat does reflect a state of molecular plasticity (c-fos $\rightarrow$ chronic FRAs), then brain areas not showing such changes may require different or additional stimulation before such adaptive effects are seen (i.e. increased threshold). Second, and possibly related to the first, is the idea that high levels of c-fos expression within these brain areas following repeated defeat may reflect physiological or behavioural processes more closely linked to the behaviour of a DOM male on the last day of testing, and therefore less likely to show adaptation. For example, subordinate male hamsters display distinct defensive postures and behaviours in response to the offensive actions of the DOM male (52, 53), and the AH, lateral VMH and dorsal PAG have been implicated in defensive responses (reviewed in (54)). Socially defeated animals also show stress-induced analgesia $(55,56)$ and increased anxiety (7-9). In this regard, the PAG has been implicated in stress-induced analgesia $(57,58)$, while the lateral septum $(45,46)$, DR (59) and LC (reviewed in (60)) have been implicated in anxiety/fear. The $\mathrm{CnF}$ is believed to serve as a relay between higher brain centres and serotonergic neurones within the brainstem involved in pain modulation (61). The extent to which activation in the aforementioned brain regions reflects the processes described above will require continued study.

\section{Conclusions}

Repeated or chronic exposure to stress can lead to pathological changes in the behaviour and physiology of an organism. In the present study, we show that repeated exposure to the stress of defeat reduced the level of c-fos mRNA within select brain regions, even though other indices of stress responsiveness remain elevated (defensive behaviour, glucocorticoid secretion). The significance of a distinction between habituating and non-habituating patterns of immediate early gene expression in the brains of chronically defeated males is presently unknown. However, it is possible that different patterns of neuronal activation observed following chronic defeat reveal distinct neurocircuits with unique qualities (e.g. function, states of neuroplasticity). Further study of the relationship of habituating and non-habituating patterns of immediate early gene expression following defeat to the function of specific groups of neurones and neurocircuits, and the significance of such effects to stress-induced pathology, is warranted.

\section{Acknowledgements}

Authors wish to thank Jim Stewart for assistance with killing the animals. This work was supported by P30-HD-18258 to Morphology Core of the NIH-NICHD Center for the Study of Reproduction at the University of Michigan, and grant P01 MH42251 to SJW.

Accepted 26 January 1999

\section{References}

1 McEwen BS, Stellar E. Stress and the individual: mechanisms leading to disease. Arch Intern Med 1993; 153: 2093-2101.

2 Checkley S. The neuroendocrinology of depression and chronic stress. Brit Med Bull 1996; 52: 597-617.

3 Blanchard DC, Spencer RL, Weiss SM, Blanchard RJ, McEwen BS, Sakai RR. Visible burrow system as a model of chronic social stress: Behavioral and neuroendocrine correlates. Psychoneuroendocrinology 1995; 20: 117-134.

4 Huhman KL, Moore TO, Ferris CF, Mougey EH, Meyerhoff JL. Acute and repeated exposure to social conflict in male golden hamsters: Increases in plasma POMC-peptides and cortisol and decreases in plasma testosterone. Horm Behav 1991; 25: 206-216.

5 Kudryavtseva NN, Bakshtanovskaya IV, Koryakina LA. Social model of depression in mice of C57BL/6J strain. Pharmacol Biochem Behav 1991; 38: 315-320.

6 Yoshimura H, Kimura N. Ethopharmacology of copulatory disorder induced by social conflict in male mice. Neurosci Biobehav Rev 1991; 15: $497-500$.

7 Heinrichs SC, Merlo Pich E, Miczek KA, Britton KT, Koob GF. Corticotropin-releasing factor antagonist reduces emotionality in socially defeated rats via direct neurotropic action. Brain Res 1992; 581: 190-197.

8 Merlo Pich E, Heinrichs SC, Rivier C, Miczek KA, Fisher DA, Koob GF. Blockade of pituitary-adrenal axis activation induced by peripheral immunoneutralization of corticotropin-releasing factor does not affect the behavioral response to social defeat stress in rats. Psychoneuroendocrinology 1993; 18: 495-507.

9 Rodgers RJ, Cole JC. Anxiety enhancement in the murine elevated plus maze by immediate prior exposure to social stressors. Physiol Behav 1993; 53: 383-388.

10 Tornatzky W, Miczek KA. Long-term impairment of autonomic circadian rhythms after brief intermittent social stress. Physiol Behav 1993; 53: $983-993$.

11 Albonetti ME, Farabollini F. Social stress by repeated defeat: Effects on social behaviour and emotionality. Behav Brain Res 1994; 62: 187-193.

12 Kupfer DJ. Biological markers of depression. In: Feighner JPBoyer WF, eds. The Diagnosis of Depression. New York: John Wiley \& Sons, 1991: 79-98.

13 American Psychiatric Association Task Force on Nomenclature and Statistics. Diagnostic and Statistical Manual of Mental Disorders. Washington, DC: American Psychiatric Association, 1980.

14 Brown GW, Harris TO. Life Events and Illness. London: Unwin Hyman, 1989.

15 Kollack-Walker S, Watson SJ, Akil H. Social stress in hamsters: Defeat activates specific neurocircuits within the brain. J Neurosci 1997; 17: 8842-8855.

16 Matsuda S, Peng H, Yoshimura H, Wen T-C, Fukuda T, Sakanaka M. Persistent c-fos expression in the brains of mice with chronic social stress. Neurosci Res 1996; 26: 157-170.

17 Morgan JI, Curran T. Stimulus-transcription coupling in neurons: Role of cellular immediate-early genes. Trends Neurosci 1989; 12: 459-462.

18 Martinez M, Phillips PJ, Herbert J. Adaptation in patterns of c-fos expression in the brain associated with exposure to either single or repeated social stress in male rats. Eur J Neurosci 1998; 10: 20-33.

19 Campeau S, Akil H, Watson SJ. Lesions of the medial geniculate nuclei specifically block corticosterone release and induction of c-fos mRNA in the forebrain associated with audiogenic stress in rats. J Neurosci 1997; 17: 5979-5992.

20 Paxinos G, Watson C. The Rat Brain in Stereotaxic Coordinates. Sydney: Academic Press 1997.

21 Cullinan WE, Herman JP, Helmreich DL, Watson SJ. A neuroanatomy of stress. In: Friedman MJCharney DSDeutch AY, eds. Neurobiological and Clinical Consequences of Stress: from Normal Adaptation to PTSD. New York: Raven Press Ltd, 1995: 3-26.

22 Watanabe Y, Stone E, McEwen BS. Induction and habituation of c-fos and zif/268 by acute and repeated stressors. Neuroreport 1994; 5: 1321-1324.

23 Chen X, Herbert J. Regional changes in c-fos expression in the basal forebrain and brainstem during adaptation to repeated stress: Correlations with cardiovascular, hypothermic and endocrine responses. Neuroscience 1995; 64: 675-685.

24 Umemoto S, Noguchi K, Kawai Y, Senba E. Repeated stress reduces 
the subsequent stress-induced expression of Fos in rat brain. Neurosci Letts 1994; 167: 101-104.

25 Umemoto S, Kawai Y, Senba E. Differential regulation of IEGs in the rat PVN in single and repeated stress models. Neuroreport 1994; 6: 201-204.

26 Smith MA, Banerjee S, Gold PW, Glowa J. Induction of c-fos mRNA in rat brain by conditioned and unconditioned stressors. Brain Res 1992; 578: $135-141$.

27 Melia KR, Ryabinin AE, Schroeder R, Bloom FE, Wilson MC. Induction and habituation of immediate early gene expression in rat brain by acute and repeated restraint stress. J Neurosci 1994; 14: 5929-5938.

28 Mamalaki E, Kvetnansky R, Brady LS, Gold PW, Herkenham M. Repeated immobilization stress alters tyrosine hydroxylase, corticotropinreleasing hormone and corticosteroid receptor messenger ribonucleic acid levels in rat brain. J Neuroendocrinol 1993; 4: 689-699.

29 Sassone-Corsi P, Sisson JC, Verma IM. Transcriptional autoregulation of the proto-oncogene Fos Nature 1988; 334: 314-319.

30 Winston SM, Hayward MD, Nestler EJ, Duman RS. Chronic electroconvulsive seizures down-regulate expression of the immediate-early genes c-fos and c-jun in rat cerebral cortex. J Neurochem 1990; 54: 1920-1925.

31 Sonnenberg JL, Macgregor-Leon PF, Curran T, Morgan JI. Dynamic alterations occur in the levels and composition of transcription factor AP-1 complexes after seizure. Neuron 1989; 3: 359-365.

32 Hope BT, Nye HE, Kelz MB, Self DW, Iadarola M, Nakabeppu Y, Duman RS, Nestler EJ. Induction of a long-lasting AP-1 complex composed of altered Fos-like proteins in brain by chronic cocaine and other chronic treatments. Neuron 1994; 13: 1235-1244.

33 Chen J, Kelz MB, Hope BT, Nakabeppu Y, Nestler EJ. Chronic fosrelated antigens: Stable variants of delta-FosB induced in brain by chronic treatments. $J$ Neurosci 1997; 17: 4933-4941.

34 Pennypacker KR, Hong JS, McMillian MK. Implication of prolonged expression of Fos-related antigens. Trends Pharmacol Sci 1995; 16: 317-321.

35 Herman JP, Cullinan WE. Neurocircuitry of stress: Central control of the hypothalamo-pituitary-adrenocortical axis. Trends Neurosci 1997; 20: $78-84$.

36 Cullinan WE, Helmreich DL, Watson SJ. Fos expression in forebrain afferents to the hypothalamic paraventricular nucleus following swim stress. J Comp Neurol 1996; 386: 88-99.

37 Kapp BS, Gallagher M, Underwood M, McNall CL, Whitehorn D. Cardiovascular responses elicited by electrical stimulation of the amygdala central nucleus in the rabbit. Brain Res 1982; 234: 251-262.

38 Iwata J, Chida K, LeDoux JE. Cardiovascular responses elicited by stimulation of neurons in the central amygdaloid nucleus in awake but not anesthetized rats resemble conditioned emotional responses. Brain Res 1987; 418: 183-187.

39 Henke PG. Electrophysiological activity in the central nucleus of the amygdala: emotionality and stress ulcers in rats. Behav Neurosci 1988; 102: $77-83$.

40 Deutch AY, Clark LS, Peacock LJ. Kainic acid stimulation of the lateral septum elicits tachycardia. Brain Res Bull 1984; 12: 209-214.

41 Henke PG. The bed nucleus of the stria terminalis and immobilization stress: unit activity, escape behavior, and gastric pathology in rats. Behav Brain Res 1984; 11: 35-45.
42 Ciriello J, Janssen SA. Effect of glutamate stimulation of bed nucleus of the stria terminalis on arterial pressure and heart rate. Am J Physiol 1993; 265: H1516-H1522.

43 Jellestad FK, Markowska A, Bakke HK, Walther B. Behavioral effects after ibotenic acid, 6-OHDA and electrolytic lesions in the central amygdala nucleus of the rat. Physiol Behav 1986; 37: 855-862.

44 Liebsch G, Landgraf $R$, Gerstberger R, Probst JC, Wotjak CT, Engelmann M, Holsboer F, Montkowski A. Chronic infusion of a $\mathrm{CRH}_{1}$ receptor antisense oligodeoxynucleotide into the central nucleus of the amygdala reduced anxiety-related behavior in socially defeated rats. Regul Pept 1995; 59: 229-239.

45 Thomas E. Forebrain mechanisms in the relief of fear: The role of the lateral septum. Psychobiology 1988; 16: 36-44.

46 Pesold C, Treit D. Excitotoxic lesions of the septum produce anxiolytic effects in the elevated plus-maze and the shock-probe burying tests. Physiol Behav 1992; 52: 37-47.

47 Casada JH, Dafny N. Restraint and stimulation of bed nucleus of the stria terminalis produce similar stress-like behaviors. Brain Res Bull 1991; 27: 207-212.

48 Canteras NS, Simerly RB, Swanson LW. Connections of the posterior nucleus of the amygdala. J Comp Neurol 1992; 324: 143-179.

49 Daval J-L, Nakajima T, Gleiter CH, Post RM, Marangos PJ. Mouse brain c-fos mRNA distribution following a single electroconvulsive shock. J Neurochem 1989; 52: 1954-1957.

50 Van de Kar LD. Forebrain pathways mediating stress-induced renin secretion. Clin Exp Pharmacol Physiol 1996; 23: 166-170.

51 Johnson AK, Cunningham JT, Thunhorst RL. Integrative role of the lamina terminalis in the regulation of cardiovascular and body fluid homeostasis. Clin Exp Pharmacol Physiol 1996; 23: 183-191.

52 Lerwill CJ, Makings P. The agonistic behaviour of the golden hamster Mesocricetus auratus (Waterhouse). Anim Behav 1971; 19: 714-721.

53 Grant EC, Mackintosh JH. A comparison of the social postures of some common laboratory rodents. Behaviour 1963; 21: 246-259.

54 Siegel A, Pott CB. Neural substrates of aggression and flight in the cat. Prog Neurobiol 1988; 31: 261-283.

55 Miczek KA, Thompson ML, Shuster L. Opioid-like analgesia in defeated mice. Science 1982; 215: 1520-1522.

56 Rodgers RJ, Hendrie CA. Social conflict activates status-dependent endogenous analgesia or hyperalgesic mechanisms in male mice: effects of naloxone on nociception and behavior. Physiol Behav 1983; 30: 775-780.

57 Bandler R, Shipley MT. Columnar organization in the midbrain periaqueductal gray: Modules for emotional expression? Trends Neurosci 1994; 17: $379-389$.

58 Behbehani MM. Functional characteristics of the midbrain periaqueductal gray. Prog Neurobiol 1995; 46: 575-605.

59 Graeff FG, Viana MB, Mora PO. Opposed regulation by dorsal raphe nucleus 5-HT pathways of two types of fear in the elevated T-maze. Pharmacol Biochem Behav 1996; 53: 171-177.

60 Bremner JD, Krystal JH, Southwick SM, Charney DS. Noradrenergic mechanisms in stress and anxiety: I. Preclinical studies. Synapse 1996; 23: $28-38$.

61 Bernard JF, Peschansi M, Besson JM. Afferents and efferents of the rat cuneiformis nucleus: an anatomical study with reference to pain transmission. Brain Res 1989; 490: 181-185. 